Vol. 5, No. 2, 2019

\author{
Mykola Voytovych ${ }^{1}$, Lev Velychko ${ }^{2}$, Roman Lampika ${ }^{3}$, Khrystyna Lishchynska ${ }^{4}$ \\ 1. Department of Engineering Mechanics, Hetman Petro Sahaidachnyi National Army Academy, Ukraine, Lviv, \\ Heroiv Maidanu Street 32, E-mail: voytovych.mykola@gmail.com \\ 2. Department of Engineering Mechanics, Hetman Petro Sahaidachnyi National Army Academy, Ukraine, Lviv, \\ Heroiv Maidanu Street 32, E-mail: Lvelychko@yahoo.com \\ 3. Department of Designing and Operation of Machines, Lviv Polytechnic National University, Ukraine, Lviv, \\ S. Bandera Street 12, E-mail: rolam2550@ukr.net \\ 4. Department of Engineering Mechanics, Hetman Petro Sahaidachnyi National Army Academy, Ukraine, Lviv, \\ Heroiv Maidanu Street 32, E-mail: K_lisch@meta.ua
}

\title{
CALCULATION OF STRENGTH OF HEATED CURVILINEAR BAR STRUCTURAL ELEMENTS OF TUBULAR CROSS-SECTIONS
}

Received: July 06, 2019 / Revised: August 18, 2019 / Accepted: August 30, 2019

(C) Voytovych M., Velychko L., Lampika R., Lishchynska Kh., 2019

Abstract. Practical importance. The analytical and numerical results obtained can be used in the study of the stress state and, respectively, to evaluate the strength and stiffness of curvilinear tubular structural elements, in particular, the pipeline bends and pipes of economizers.

The purpose. Investigation of the temperature field and the thermoelastic state of the curvilinear rod with a tubular cross-section caused by it; analysis of the influence of geometrical and thermophysical parameters on the characteristics of its temperature field, as well as on the forces and moments in it.

The research method. The object of research is the curvilinear rod with a tubular crosssection, which is in the conditions of convective heat exchange with the external and internal environments. The thermal conductivity equation for a large curvature rod was used to describe its temperature field. For determining the characteristics of the stress-strain state due to the described temperature field, the equations of thermal elasticity of curvilinear rods in displacements were used; the case was analyzed when radial and tangential displacements are absent in the extreme crosssections of the curvilinear part of the rod, and there are no turns of these cross-sections.

Results. The studies have shown that the specific coefficients of heat transfer of the outer and inner surfaces of the rod affect its stress state in a different way; as the heat transfer coefficient from the outer surface increases, the absolute values of the longitudinal and transverse forces, as well as of the bending moment, decrease, and with the increase of the heat transfer coefficient from the inner surface, they increase. In contrast to the stress problem, in the case of heating, the value of the bending moment in a certain cross-section of a curvilinear rod depends on the geometrical parameters of the cross-section.

The scientific novelty. Analytical-numerical method shows for the first time that there is such a cross-section in which the heat-induced bending moment changes its sign; the position of this cross-section depends on the curvature of the axis, the thickness of the wall, the bend angle of the curvilinear part of the rod and practically does not depend on the specific coefficients of heat transfer from its inner and outer surfaces. There are values of the bend angle at which the bending moment and transverse force in the curvilinear part of the rod reach their maximums.

Keywords: temperature field, temperature deformations, curvilinear rod, tubular crosssection, thermophysical parameters.

\section{Introduction}

The current state of scientific and technological progress imposes increased requirements on engineering structures. They should be sufficiently strong and reliable in the ever-widening ranges of the 
changing of various parameters that characterize the conditions of their manufacture and operation. The introduction into practice of new, in most cases more intensive, technological processes, the increasing complexity of operating conditions of modern engineering structures lead to the need to take into account not only the stress loading used traditionally during the calculations of the strength, but also the effect of fields of different physical nature, in particular, various thermal actions on the stress-strain state.

\section{Review of Modern Information Sources}

A number of works are devoted to the problem of determination of temperature stresses in rod elements of engineering structures. Thermal stresses and deformations in homogeneous isotropic rings are considered in [1]; the stressed state of heated multi-layered curved bars is investigated in [2]. The main relationships of the thermoelasticity of the rods are considered in the monograph [3]. The work [4] is devoted to the calculation of composite axisymmetric annular structural elements in the conditions of heating, and the work [5] presents the calculation of heated multi-layered rings. The relevant sections of monographs $[6,7]$ are devoted to the study of the stress-strain state of pipeline elements under heating conditions. A characteristic feature of these works is that the temperature fields of the considered structural elements are accepted known, that is, given. This approach does not allow the heating conditions, i.e. the operating conditions, to be completely taken into account; in addition, there is a question of practical implementation of the given temperature fields.

Obviously, to study more fully the effect of heating on the stress state of structural elements, it is necessary to first solve the problem of thermal conductivity. This approach makes it possible to take more fully into account the operating conditions, as well as to formulate the problems of optimization of the stress-strain state and strength of such elements with the choice as the control functions of the quantities that characterize the heating conditions.

\section{Problem Statement}

Important elements of various engineering structures are tubular curvilinear rods (pipeline bends, pipes of economizers, etc.). Such elements operate quite often at high or low temperatures $[6,7,8,9]$. Because of this, the study of the effect of thermophysical and geometrical parameters on their stress-strain state and strength is relevant.

\section{Objectives and Problems of Research}

This work is aimed to study the temperature field and the thermoelastic state of the curvilinear rod with a tubular cross-section, the axis of which is an arc of a circle, which is connected with two rays (the pipeline bend is modeled by the curvilinear part of the rod); analysis of the influence of geometrical and thermophysical parameters of the bend on the integral characteristics of its temperature field and the forces and moments determined by this field.

\section{Main Material Presentation}

Formulation of the research problem. Consider an isotropic rod of a tubular cross-section, the axis of which is an arc of a circle of length $l$, which is connected with two rays. The cross-section of the rod is limited by concentric circles of radii $R_{1}$ and $R_{2}\left(R_{1}>R_{2}\right)$. Let the inner surface of the rod $S_{2}$ be washed with some environment (e.g., flowing fluid or gas) with temperature $t_{c}^{(2)}$, and the outer surface $S_{1}$ with an environment with temperature $t_{c}^{(1)}$. Determine the temperature field and the resulting stress state of this rod element (the pipeline bend).

The temperature field of the pipeline bend. We attribute the considered curvilinear section of the pipeline to the mixed coordinate system xys: coordinate $s$ will be counted along the axis of the rod, and the $o x$ and $o y$ axes of rectangular coordinates will be collocated with its principal normal and binormal lines. Suppose that the temperatures $t_{c}^{(1)}$ and $t_{c}^{(2)}$ are constant; the heat transfer coefficients $\varepsilon_{1}$ and $\varepsilon_{2}$ from both the outer and inner surfaces of the rod are also constant. The temperature field of the curvilinear part of the rod will be described by the following system of differential equations [10]: 


$$
\begin{aligned}
& \Lambda\left(A_{00} \frac{d^{2} T}{d s^{2}}+A_{10} \frac{d^{2} \Theta_{y}}{\partial s^{2}}\right)=E_{00} T+E_{10} \Theta_{y}+T_{00}^{(c)} \\
& \Lambda\left(A_{10} \frac{d^{2} T}{d s^{2}}+A_{20} \frac{d^{2} \Theta_{y}}{\partial s^{2}}\right)=E_{10} T+\left[E_{20}+R_{x}^{-1}\right] \Theta_{y}+T_{10}^{(c)} \\
& \Lambda_{s} \frac{d^{2} \Theta_{x}}{d s^{2}}=\left(E_{02}+R_{y}^{-1}\right) \Theta_{x}
\end{aligned}
$$

and of the rectilinear parts of the rod will be described by the following system:

$$
\begin{aligned}
& \Lambda \frac{d^{2} T}{d s^{2}}=E_{00} T+T_{00, *}^{(c)} ; \\
& \Lambda \frac{d^{2} \Theta_{y}}{\partial s^{2}}=\left(E_{20, *}+R_{x}^{-1}\right) \Theta_{y} ; \\
& \Lambda \frac{d^{2} \Theta_{x}}{\partial s^{2}}=\left(E_{02, *}+R_{y}^{-1}\right) \Theta_{x} .
\end{aligned}
$$

The notation used here:

$$
\begin{gathered}
A_{i j}=\frac{1}{F} \iint_{D}\left(1-\frac{x}{r_{0}}\right)\left(\frac{x}{\delta y}\right)^{i}\left(\frac{y}{\delta x}\right)^{j} d F, \\
E_{i j}=-\sum_{k=1}^{2} \oint_{L_{k}} \varepsilon_{k}\left(1-\frac{x}{r_{0}}\right)\left(\frac{x}{\delta y}\right)^{i}\left(\frac{y}{\delta x}\right)^{j} d l, \\
T_{i j}=-\sum_{k=1}^{2} \oint_{L_{k}} \varepsilon_{k}\left(1-\frac{x}{r_{0}}\right)\left(\frac{x}{\delta y}\right)^{i}\left(\frac{y}{\delta x}\right)^{j} t_{c}^{(r)} d l ; \\
E_{i j, *}=E_{i j / r_{0} \rightarrow \infty} ; T_{i j, *}^{(c)}=T_{i j / r_{0} \rightarrow \infty}^{(c)}, \Lambda=\lambda F ; R_{x, y}^{-1}=F \delta_{y, x}^{-1} \lambda ;
\end{gathered}
$$

$\lambda$ is the coefficient of thermal conductivity of the rod material, $\delta_{x}\left(\delta_{y}\right)$ is the distance from the axis $o x$ (oy) to the farthest point on the rod cross-section; $r_{0}$ is the radius of the axis of the curvilinear part of the rod; $D$ is the cross-sectional region of the bend, and $F$ is its area.

Assuming that the temperature at the ends of the rod (distant to infinity) is limited, the solutions of the system of equations (1) and (2) for the curvilinear and rectilinear parts of the rod, respectively, are obtained as:

$$
\begin{gathered}
T^{(1)}=\sum_{i=1}^{2} C_{i} \operatorname{ch} \lambda_{i} \varphi+T_{r}^{(1)}+T_{r}^{(0)}, \quad \Theta_{x}=0, \quad\left(|\varphi| \leq \varphi_{0}\right) \\
\Theta_{y}^{(1)}=a_{0}\left(\sum_{i=1}^{2} C_{i}\left(\lambda_{i}^{2}+b_{0}\right) \operatorname{ch} \lambda_{i} \varphi+b_{0} T_{r}^{(1)}+\Theta_{r}^{(0)}\right) ; \\
T^{(0)}=\left(T_{1}^{(1)}\left(\varphi_{0}\right)-T_{r}^{(0)}\right) e^{-\kappa_{1} \xi}+T_{r}^{(0)}, \quad \Theta_{x}^{(0)}=0, \quad \Theta_{y}^{(0)}=\Theta_{y}^{(1)}\left(\varphi_{0}\right) e^{-\kappa_{2} \xi} \quad(|\xi| \geq 0) .
\end{gathered}
$$

The notation used here:

$$
\begin{gathered}
\lambda_{1,2}=\frac{1}{\sqrt{2}}\left(b_{0}-(\kappa d)^{-1} a_{0}(d+2)\right)^{\frac{1}{2}}\left[1 \pm\left(1+\left(2 a_{0} b_{0} \kappa+b_{0} \kappa^{2}+a_{0} \kappa+a_{0}^{2}\right)\left(d a_{0} b_{0} \kappa-d a_{0}^{2}-2 a_{0}^{2}\right)\right)^{\frac{1}{2}}\right]^{\frac{1}{2}} ; \\
\kappa_{i}=\lim _{\kappa \rightarrow 0} \kappa \lambda_{i} ; \quad \varphi_{n m}=\kappa_{n} \operatorname{ch} \lambda_{m} \varphi_{0}+\lambda_{m} s h \lambda_{m} \varphi_{0} ; \\
\Delta=\left(\lambda_{2}^{2}+\mathrm{b}_{0}\right) \varphi_{11} \varphi_{22}-\left(\lambda_{1}^{2}+\mathrm{b}_{0}\right) \varphi_{12} \varphi_{21} ; \\
\mathrm{C}_{1}=\Delta^{-1}\left[\left(-\kappa_{1}\left(\lambda_{2}^{2}+b_{0}\right) \varphi_{22}+\kappa_{2} b_{0} \varphi_{12}\right) T_{r}^{(1)}+\kappa_{2} \varphi_{12} \Theta_{r}^{(0)}\right], \\
\mathrm{C}_{2}=\Delta^{-1}\left[\left(-\kappa_{1}\left(\lambda_{1}^{2}+b_{0}\right) \varphi_{21}-\kappa_{2} b_{0} \varphi_{11}\right) T_{r}^{(1)}-\kappa_{2} \varphi_{11} \Theta_{r}^{(0)}\right],
\end{gathered}
$$




$$
\begin{gathered}
b_{0}=2\left(B_{i}^{(1)}+B_{i}^{(2)}\right) \kappa^{-2}\left(1-\delta^{2}\right)^{-1}-\frac{1}{2}\left(1+\kappa a_{0}^{-1}\right), \\
a_{0}=-\kappa\left(1-\delta^{2}\right)\left(1-\delta^{2}+2\left(B_{i}^{(1)}+\delta^{2} B_{i}^{(2)}\right)\right)^{-1} ; \\
T_{r}^{(1)}=\left(\lambda_{1} \lambda_{2}\right)^{-2} d^{-1}\left(B_{1}^{(1)}+\delta^{2} B_{i}^{(2)}\right) \Theta_{r}^{(0)}, \quad T_{r}^{(0)}=t_{c}^{(2)}+\left(B_{i}^{(2)}\right)^{-1} \Theta_{r}^{(0)}, \\
\Theta_{r}^{(0)}=B_{i}^{(1)} B_{i}^{(2)}\left(B_{i}^{(1)}+B_{i}^{(2)}\right)^{-1}\left(t_{c}^{(1)}-t_{c}^{(2)}\right) ; \quad l=2 r_{0} \varphi_{0}, \\
\mathrm{~d}=2\left(\left(1-\kappa^{2}\right)^{\frac{1}{2}}+\left(1-\kappa^{2} \delta^{2}\right)^{\frac{1}{2}}\right)-1 ; \quad \mu=t_{c}^{(2)}: t_{c}^{(1)}, \quad \delta=R_{2} R_{1}^{-1}, \\
\kappa=R_{1} r_{0}^{-1}, \quad \xi=S R_{1}^{-1}, \quad B_{i}^{(\kappa)}=\varepsilon_{k} R_{\kappa} \lambda^{-1} \quad(\kappa=1,2) ;
\end{gathered}
$$

the value $\varphi_{0}=0$ corresponds to the plane of symmetry of the bend.

A parametric study of the resulting solution was performed. The distribution of the characteristics of $T$ and $\Theta_{y}$ of the temperature field of the pipeline bend along its axis is presented in Fig. 1 by dashed and solid lines respectively; in these calculations, it was accepted: $B_{i}^{(1)}=0.05 ; \delta=0.3 ; \mu=0.1 ; \varphi_{0}=0.5 \pi$. The graphs in Fig. 1 were constructed for various values of the criterion $B_{i}^{(2)}$ (indicated near the corresponding curves). The notation used here $\bar{T}=T: t_{c}^{(1)}, \bar{\Theta}=\Theta_{y}: 0.01 t_{c}^{(1)}$.

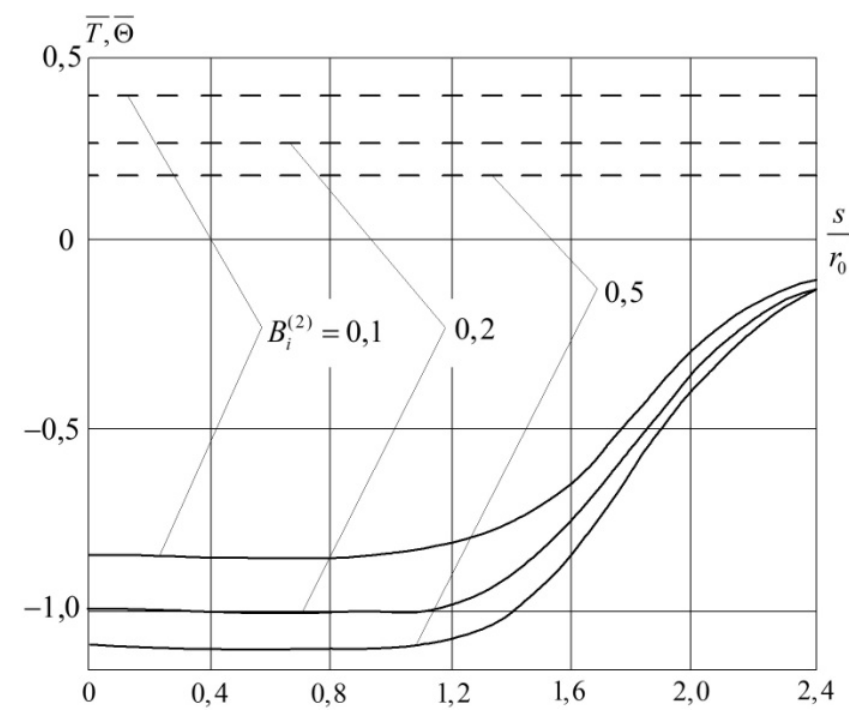

Fig. 1. The distribution of the average temperature $\bar{T}$ and temperature difference $\bar{\Theta}$ along the pipeline bend

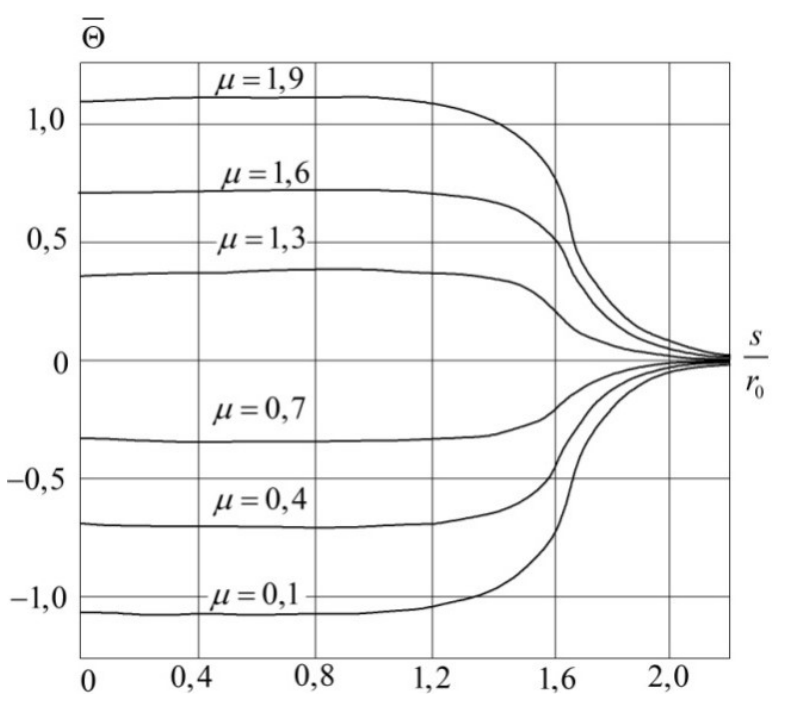

Fig. 2. Changing the temperature difference $\bar{\Theta}$ along the bend axis at different ratios of temperatures of the external and internal environments

These graphs show that the average temperature $T$ in the curvilinear $\left(S / r_{0} \leq 1.57\right)$ and rectilinear $\left(S / r_{0} \geq 1.57\right)$ sections of the pipeline almost coincide, that is, the average rod temperature slightly depends on its curvature. The temperature difference $\Theta_{y}$ is only in the bend zone and approaching zero when distant from this zone. In the case under study (temperatures of washing environments and heat transfer coefficients are constant, the pipeline cross-section is limited by concentric circles), it is due only to curvature; these circumstances explain its relatively small value (taking into account $\Theta_{y}$ when determining the temperature gives a correction of about $7 . . .9 \%$ ).

The variation of the magnitude $\Theta_{y}$ along the bend axis at different values of the ratio of the temperatures of the external and internal environments is shown in Fig. 2 (for $B_{i}^{(1)}=0.05 ; B_{i}^{(2)}=0.3$ and for the above values of other parameters). 
Thermoelastic state of the pipeline bend. To determine the radial and tangential displacements of the rod ( $u$ and $v$, respectively) we use the equations [11], which, taking into account temperature deformations, take the form:

$$
\begin{aligned}
& r_{0} \frac{d^{2} u}{d s^{2}}+\frac{u}{r_{0}}=\left(\frac{1}{r_{0}}-\frac{1}{\eta_{0}}\right)\left(\frac{M}{E F}+\frac{W_{y}}{F} \alpha \Theta_{y}\right)-\alpha T, \\
& v=\int\left(u+\frac{1}{E F}\left(r_{0} N-M\right)+\alpha\left(r_{0} T-\frac{W}{F} \Theta_{y}\right)\right) d s .
\end{aligned}
$$

where $\alpha$ is the coefficient of linear expansion of the rod material; $\eta_{0}$ is the distance between the neutral (for the pure bending) layer and the axis of the rod.

Substituting the expressions (5) into these equations instead of $T$ and $\Theta_{y}$, we solve them. To determine the constants of integrations, we use the conditions that the sections $\varphi= \pm \varphi_{0}$ lack radial and tangential displacements, as well as the turns of these sections. Based on the obtained solution using the formulas for the longitudinal and transverse forces in the curvilinear rod [12], we derive the following expressions for the bending moment $M$, the longitudinal force $N$, and the transverse force $Q$ :

$$
\begin{gathered}
M=M_{0}+r_{0} Q_{0}\left(\operatorname{ctg} \varphi_{0}-\sin ^{-1} \varphi_{0} \cos \varphi\right) ; \\
N=Q_{0} \sin ^{-1} \varphi_{0} \cos \varphi, \quad Q=Q_{0} \sin ^{-1} \varphi_{0} \sin \varphi ; \\
Q_{0}=E \alpha F\left(\left(2(1+\mathrm{d}) \varphi_{0}\right)^{-1}-\frac{1}{2}\left(\operatorname{ctg} \varphi_{0}+\varphi_{0} \sin ^{-1} \varphi_{0}\right)\right)\left[-d\left(\mathrm{~T}_{r}^{(1)}+T_{r}^{(0)}\right)+\right. \\
+\frac{1}{4} a_{0} \kappa\left(1+\delta^{2}\right) \sum_{i=1}^{2} C_{i}\left(\lambda_{i}^{2}+b_{0}\right)\left(\lambda_{i} \varphi_{0}\right)^{-1} \operatorname{sh} \lambda_{i} \varphi_{0}-\sum_{i=1}^{2} C_{i}\left(\frac{1}{4} a_{0} \kappa\left(1+\delta^{2}\right)\left(\lambda_{i}^{2}+b_{0}\right)+d\right) \times \\
\left.\times\left(1+\lambda_{i}^{2}\right)^{-1}\left(\operatorname{ch} \lambda_{i} \varphi_{0}+\lambda_{i} \operatorname{ctg} \varphi_{0} \operatorname{sh} \lambda_{i} \varphi_{0}\right)\right] ; \\
\mathrm{M}_{0}=E \alpha F R_{1}\left(\frac{1}{4} a_{0}\left(1+\delta^{2}\right) \sum_{i=1}^{2} C_{i}\left(\lambda_{i}^{2}+b_{0}\right)\left(\lambda_{i} \varphi_{0}\right)^{-1} \operatorname{sh} \lambda_{i} \varphi_{0}-b_{0} T_{r}^{(1)}+\Theta_{r}^{(0)}+\right. \\
\left.+\left(\operatorname{ctg} \varphi_{0}-\left(2(1+d) \varphi_{0}\right)^{-1}\right) \frac{Q_{0}}{\kappa}\right) .
\end{gathered}
$$

A numerical analysis of the obtained characteristics of the stress-strain state of the pipeline bend was carried out; some of the obtained results are presented in Figs. 3 and 4. The distribution of dimensionless parameters of the moment and forces along the axis of the bend

$$
\bar{M}=\left(E \alpha t_{c}^{(1)} F R_{1}\right)^{-1} M, \quad \bar{N}=\left(E \alpha t_{c}^{(1)} F\right)^{-1} N, \quad \bar{Q}=\left(E \alpha t_{c}^{(1)} F\right)^{-1} Q
$$

is represented by solid, dot-dashed and dashed lines, respectively, in Figs. 3 at various values of the specific coefficient of heat transfer $B_{i}^{(2)}$

$$
\left(B_{i}^{(1)}=0.05 ; \mu=0.5 ; \delta=0.5 ; \kappa=0.5 ; \varphi_{0}=0.5 \pi\right) .
$$

The effect of the parameter $\delta$ (the ratio of the radii of the outer and inner contours of the bend cross-section) on the maximum value of the bending moment

$$
\bar{M}_{\max }=\left(\pi E \alpha t_{c}^{(1)} F R_{1}^{3}\right)^{-1} M_{\max }
$$

is illustrated by the curves shown in Fig. $4\left(B_{i}^{(1)}=B_{i}^{(2)}=0.3 ; \varphi_{0}=0.5 \pi ; \mu=12.5\right)$.

\section{Results of the studies and discussion}

From the graphs given in Figs. 1 and 2 we can conclude that the values of the average temperature $T$ in the curvilinear $\left(\mathrm{S} / \mathrm{r}_{0} \leq 1.57\right)$ and rectilinear $\left(\mathrm{S} / \mathrm{r}_{0} \geq 1.57\right)$ sections of the pipeline practically coincide, that is, the average rod temperature slightly depends on its curvature. The temperature difference $\Theta_{y}$ is only in the bend zone and approaching zero when distant from this zone. In the case under study (temperatures 
of washing environments and heat transfer coefficients are constant, the pipeline cross-section is limited by concentric circles), it is due only to curvature; these circumstances explain its relatively small value (taking into account $\Theta_{y}$ when determining the temperature gives a correction of $7 \ldots 9 \%$ ).

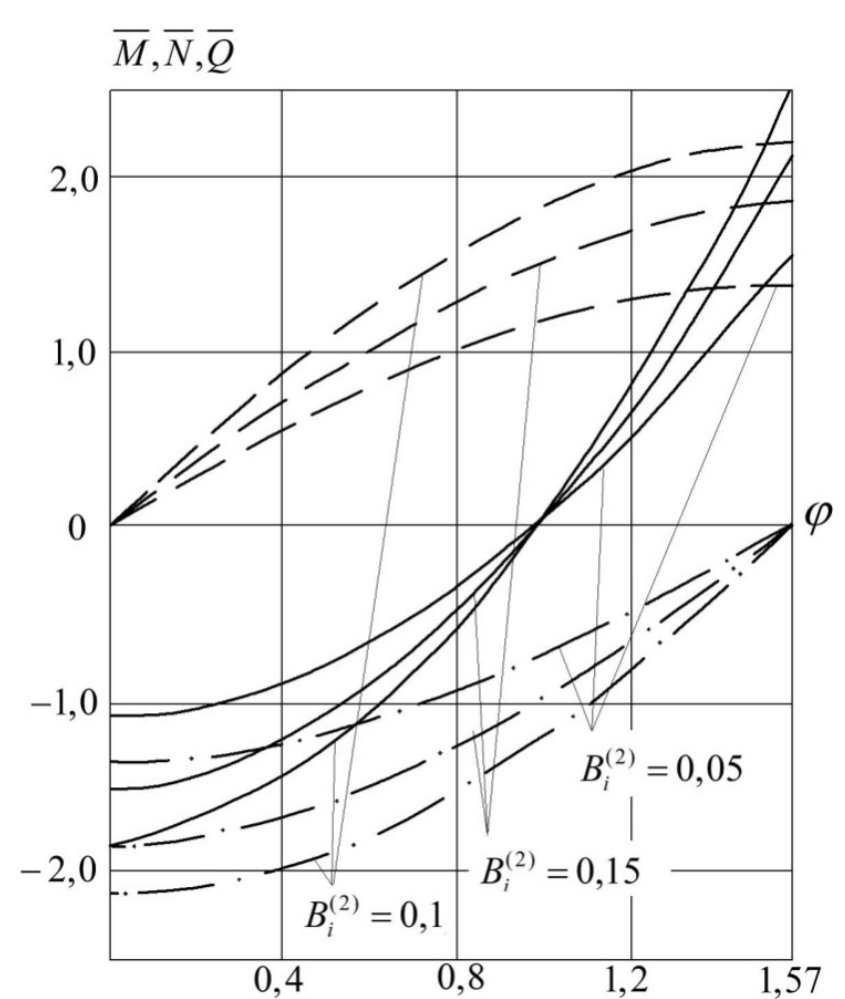

Fig. 3. The distribution of the bending moment $\bar{M}$ (solid lines), longitudinal force $\bar{N}$ (dot-dashed lines), and transverse force $\bar{Q}$ (dashed lines) along the axis of the bend, at various values of the criterion $B_{i}^{(2)}$

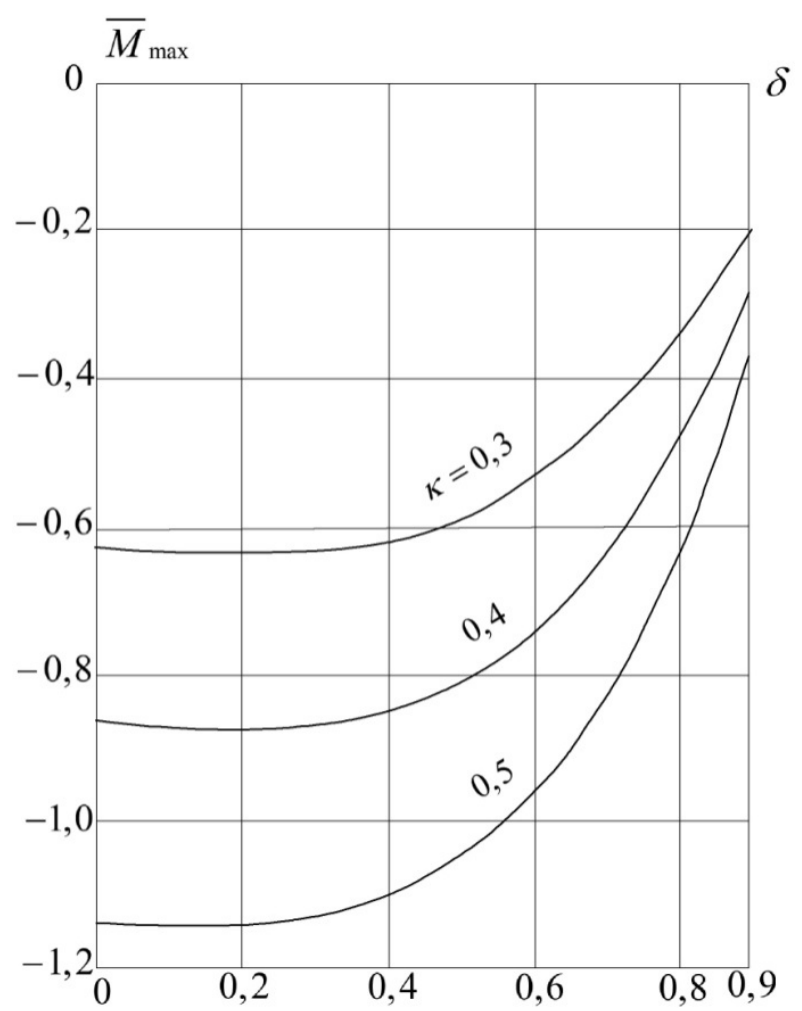

Fig. 4. The dependence of the maximum value of the bending moment $\bar{M}_{\max }$ on the ratio of the radii of the outer and inner contours of the bend cross-section

The obtained numerical results, in particular, presented in Figs. 3 and 4 show that:

- the criteria $B_{i}^{(1)}$ and $B_{i}^{(2)}$ affect the stress state of the bend in a different way; as the parameter $B_{i}^{(1)}$ characterizing heat exchange with the external environment increases, the absolute values of the moment $M$ and forces $N$ and $Q$ decrease, and with the increase of the parameter $B_{i}^{(2)}$ characterizing heat exchange with the internal environment, their values increase;

- there exists such a cross-section of the bend, in which the bending moment changes its sign; the position of this section depends on geometrical parameters $\kappa, \delta, \varphi_{0}$ and practically does not depend on the specific coefficients of heat transfer $B_{i}^{(1)}$ and $B_{i}^{(2)}$;

- in the case of heating, the value of the bending moment in the pipeline bend at a certain crosssection position depends on the geometrical parameters of the cross-section;

- there exist such values of the angle $\varphi_{0}$, that is, $\varphi_{0}=\varphi_{l}^{(1)}$ and $\varphi_{0}=\varphi_{l}^{(2)}$ (in the considered cases, $\left.\varphi_{l}^{(1)}=\varphi_{l}^{(2)} \approx 0.25 \pi\right)$ at which the bending moment and transverse force in the bend reach their maximums.

\section{Conclusions}

Based on the material presented, we can draw the following conclusions.

A method of calculating the thermal stress state of curvilinear rod elements of tubular sections has been proposed. Based on this method, the temperature field of the pipeline bend which is under convective heat exchange with the external and internal environments was studied, and its stress-strain state caused by 
this field was also investigated. It was found that the criteria $B_{i}^{(1)}$ and $B_{i}^{(2)}$ have different effects on the stress state of the pipeline bend: the absolute values of the bending moment, transverse and longitudinal forces decrease with the increase of the parameter $B_{i}^{(1)}$ that characterizes heat exchange with the external environment, and with the increase of the parameter $B_{i}^{(2)}$ characterizing heat exchange with the internal environment, their values increase. The bending moment in a curvilinear rod in the case of heating depends on the geometrical parameters of its cross-section, whereas in the case of a stress problem, it does not.

\section{References}

[1] B. F. Boley, "On thermal stresses end deflections on thin rings", Inter. J. Mech. Sci., vol. 11 (9), pp. 781-789, 1969.

[2] H. Lok, H. D. Conway, "Thermal stresses in multi-layered curved bars", Fibre Sci. and Technol., vol. 9 (2), pp. 135-151, 1976.

[3] I. A. Birger, B. F. Shorr, Termoprochnost' detaley mashin [Thermal strength of machine parts]. Moscow, Russia: Mashinostroenie Publ., 1975. [in Russian].

[4] V. A. Knyazeva, "Raschet sostavnykh osesimmetrichnykh kol'tsevykh konstruktsiy" ["Calculation of composite axisymmetric ring structures"], Izvestiya vuzov. Mashinostroyeniye [News of Universities. Mechanical Engineering], vol. 4, pp. 10-15, 1979. [in Russian].

[5] G. N. Feodosiev, "O zadache termouprugosti dlya mnogosloynykh kolets" ["On the problem of thermoelasticity for multilayer rings"], Izvestiya vuzov. Mashinostroyeniye [News of Universities. Mechanical Engineering], vol. 8, pp. 13-17, 1970. [in Russian].

[6] D. L. Kostovetskiy, Prochnost' truboprovodnykh sistem energeticheskikh ustanovok [Durability of pipeline systems of power plants]. Leningrad, Russia: Energiya Publ., 1973. [in Russian].

[7] A. G. Kamerstein, V. V. Rozhdestvenskiy, M. N. Ruchimskiy, Raschet truboprovodov na prochnost'. Spravochnaya kniga [Strength calculation of pipelines. Reference book]. Moscow, Russia: Nedra Publ., 1969. [in Russian].

[8] G. Elter, "Zur Bewertung von Spannungen in Rohrleitungen infolge Wärmetauschen des Systems" ["On the evaluation of stresses in pipelines caused by heat exchange of the system"], T.V., vol. 15 (1), pp. 25-28, 1974. [in German].

[9] M. A. Axelrod, P. V. Chukanov, N. D. Mishura, "Korozionno-ustalostnoye razrusheniye gibov trub vodyanogo ekonomayzera" ["Corrosion-fatigue failure of water economizer pipe bends"], Teploenergetika [Heat Power Engineering], vol. 1, pp. 45-47, 1973. [in Russian].

[10] Ya. S. Podstrigach, Yu. A. Chernukha, N. I. Voitovich, "K opredeleniyu temperaturnykh poley i napryazheniy v obolochkakh, sopryazhennykh cherez sterzhen" ["On the determination of temperature fields and stresses in shells conjugated through a rod"], in Matematicheskiye metody v termomekhanike [Mathematical methods in thermomechanics]. Kiev, Ukraine: Naukova Dumka Publ., 1978, pp. 3-11. [in Russian].

[11] S. P. Timoshenko, Soprotivleniye materialov [Strength of materials]. Kyiv, Ukraine: Vyshcha Shkola Publ., 1973. [in Russian].

[12] V. A. Svetlitskiy, Mekhanika sterzhney. Chast 1 [Mechanics of rods. Part 1]. Moscow, Russia: Vysshaya Shkola Publ., 1987. [in Russian]. 